\title{
Media portrayal of child abuse in Sri Lanka and the impact of two incidents of child abuse on media coverage
}

\author{
A Rodrigo, $\mathrm{N}$ Liyanage
}

\section{Background}

Child maltreatment is increasingly being recognised as an important public health issue in 'Sri Lanka. Most public knowledge in Sri Lanka on this issue, and direction for public policy, originate from mass media, which may sensationalise the issue.

Aims

This paper evaluates the themes and major discourses present in Sri Lankan print media on child abuse, and aims to determine if content, style and frequency of these news items have been affected by the tragic child abuse-murder incidents in 2015.

\section{Methods}

Articles on child abuse and their readers' comments were manually selected from the websites of the two daily newspapers with highest readership in Sri Lanka during two 3-month periods, before and after the above mentioned incidents. A combination of qualitative and quantitative methods were used to analyze the findings.

\section{Results}

The number of articles relating to child abuse increased significantly from $0.6 \%$ to $5 \%$ of the total articles reviewed in the two periods. The focus of the articles changed from merely reporting facts and highlighting the evil nature of child abuse perpetrators, to inefficiency of law enforcement authorities in finding and punishing perpetrators. Readership and online comments on these articles increased significantly in the post-incident period. Capital punishment for perpetrators was suggested by many readers in the post-incident period.

\section{Conclusion}

The Sri Lankan public is very sensitive to news on child abuse with formation of firm, at times extreme, viewpoints on how to manage this issue. Thus responsible and accurate depiction of child abuse by the media is important.

Key words: depiction; child abuse

SL J Psychiatry 2016; 7(2): 3-7

\section{Introduction}

Child maltreatment is increasingly being recognised as an important public health issue in Sri Lanka. Available data in Sri Lanka, though limited, suggests the annual incidence of sexual abuse to be more than 6000, and that $40.7 \%$ of parents have physically abused their children in the previous month (1). A study done among school boys in Colombo reported that $78.5 \%$ students had experienced sexual harassment and $21.9 \%$ had experienced sexual abuse (2). While more research is being done about child abuse in the country, for a vast majority of Sri Lankans, knowledge on this issue comes from the mass media. The Sri Lankan media have been essential to the growth of society's awareness of child abuse and to the task of placing this important problem in the minds of the public and on the political agenda in Sri Lanka (3). However, media reports on child abuse have been criticised around the globe for the sensational, superficial, stereotypical and uncritical nature and potential negative consequences of such media portrayal (4). Kitzinger pointed out that media is a 'business of finding, constructing and selling news, requiring immediacy and drama' which reinforces popular stereotypes and is not necessarily reflective of accurate information (5). This value laden process is highly influenced by popular culture and moral-socio-political values rather than scientific research (6).

Sri Lanka witnessed several children losing their lives and enduring unspeakable physical and emotional anguish as a result of child abuse in the 2015. Two deaths of children secondary to child sexual abuse received round the clock media coverage through print, electronic and web based media. A 17 year old girl from Jaffna (Northern town in Sri Lanka) was abducted on her way to school, gang raped and murdered on $13^{\text {th }}$ of May 2015. Four months later, a 5 year old girl was found strangled to death after being sexually assaulted, on $13^{\text {th }}$ September 2015, after she was reported missing from her home in Kotadeniyawa (a village in the western part of Sri Lanka) the previous night. The media portrayal of these incidents were described by some as 'sensationalized', and their deleterious consequences have been documented. 
Therefore we aimed to evaluate the themes and major discourses present in Sri Lankan print media on child abuse and to determine if content, style and rates of these news items have been affected by the well-known, yet tragic child abuse-murder incidents in 2015. It was hypothesised that the extent and nature of print media reportage would be impacted by these incidents. We also studied how readers have perceived this news by analysing consumption and reader comments.

Scientific research on analysis of media representation of child abuse in non-Western contexts is scarce. To the best of our knowledge this is the first of such studies in South Asia. No study has examined the public perception of media coverage of child abuse.

\section{Methodology}

Two daily newspapers with highest readership in Sri Lanka, Lankadeepa and Divaina websites were examined for coverage of child abuse (7). Circulation of these two Sinhala language newspapers surpasses combined circulation of all their competitors taken together. Articles on the subject of child abuse and children's issues were manually selected from the newspaper websites during 6 months in 2015. The time frame of the study was two 3-month blocks, selected to provide a comparative period of 3 months either side of the above mentioned incidents, from $13 / 02 / 2015$ to $12 / 05 / 2015$ and from $14 / 09 / 2015$ to $13 / 12 / 2015$. A combination of qualitative and quantitative methodology was used to analyse the coverage. The Lankadeepa website allows readers to comment about the article and the site shows how many times it has been read. Thematic analysis was performed on news items and readers' comments (only on the Lankadeepa website) by grouping them and then identifying themes by repeated reading, recording of detailed analytical notes and discussion between the two authors throughout the data coding process. Discourse or media framing analysis was performed on the coverage by analysing the manifest content of each item, which was then categorised and coded in terms of: headline, visual display of information, number of photos, tone, and information in the article. This framework for coding was modified from previous similar research.

\section{Results}

A total of 6841 newspaper articles (3027 and 3814 in the Lankadeepa and Divaina websites respectively) during the first 3 months, and 5905 articles (2819 and 3076 in the Lankadeepa and Divaina websites respectively) during the second 3 months were studied. Out of these 12746 newspaper articles, 339 articles were related to child abuse (Table 1). There was a clear increase in the extent of the media coverage in both papers concerned, during the second 3-months. While most of the news articles were directly or indirectly related to the child abuse- murder incidents, unrelated articles on child abuse almost doubled (78\%). Change in public perception was also marked, with more than 30 fold and 3 fold increase in readership and comments, respectively.

\begin{tabular}{|c|c|c|}
\hline & $\begin{array}{c}\text { First } 3 \text { months } \\
\text { (\% of total articles) }\end{array}$ & $\begin{array}{l}\text { Second } \\
3 \text { months }\end{array}$ \\
\hline Lankadeepa & $14(0.5 \%)$ & $120(4.3 \%)$ \\
\hline Divaina & $29(0.8 \%)$ & $176(5.7 \%)$ \\
\hline Total & $43(0.6 \%)$ & $296(5.0 \%)$ \\
\hline $\begin{array}{l}\text { Average times an } \\
\text { article was accessed }\end{array}$ & 115.7 & 5483 \\
\hline Number of comments & 2.4 & 12.2 \\
\hline
\end{tabular}

\section{Thematic analysis}

There were significant changes in the predominant themes of news coverage following the incidents (Table 2). There was a marked increase in themes of 'inefficiency of law enforcement authorities to find perpetrators', 'increasing threat towards Sri Lankan children than ever before', 'community reaction towards child abuse' and 'poor parenting makes children vulnerable'; while in comparison, the proportion of themes related to 'reporting of mere facts', 'evil nature of the perpetrators' and 'contribution of victim towards being subjected to abuse' were reduced. Similar changes have been seen in the readers' comments (Table 2). The most striking change following the incidents was a large number of readers commenting on giving capital punishment to the perpetrator, while only one did so prior to these two incidents.

\section{Discourse analysis}

Discourse analysis demonstrated a marked increase in the prominence given to the news coverage following the incidents, in terms of inclusion of pictures and featuring of an editorial and top story. Increase in catchy headlines and use of pejorative or harsh language indicated more sensational media coverage in the second 3 months of the study.

\section{Discussion}

It is clear that after the incident the extent of media coverage changed significantly, and there was a marked difference in the nature of news articles. Discourse analysis demonstrated increase in sensationalism, with more attention-grabbing presentation of news items. 
Table 2. Thematic analysis of the media coverage on child abuse

\begin{tabular}{|c|c|}
\hline $\begin{array}{l}\text { First } 3 \text { months } \\
\qquad(n=43)\end{array}$ & $\begin{array}{c}\text { Second } 3 \text { mor } \\
(n=296)\end{array}$ \\
\hline 23 (53.5\%) & 50 (16.9\%) \\
\hline 1 (2.3\%) & 67 (22.6\%) \\
\hline $2 \quad(4.6 \%)$ & 30 (10.1\%) \\
\hline 0 & $28 \quad(9.5 \%)$ \\
\hline 0 & $28 \quad(9.5 \%)$ \\
\hline 12 (27.9\%) & $25 \quad(8.4 \%)$ \\
\hline 0 & $17 \quad(5.7 \%)$ \\
\hline $2 \quad(4.6 \%)$ & $9 \quad(3.0 \%)$ \\
\hline
\end{tabular}

Table 3. Thematic analysis of the readers' comments the media coverage on child abuse

1. Reporting of mere facts

$(3.0 \%)$

Inefficiency of the law enforcement authorities/
government to find the perpetrators

3. Increasing threat towards Sri Lankan children / Sri Lankan children are at risk more than ever before

4. Community reaction towards child abuse

5. Inadequacy of punishment against child abuse perpetrators

6. Evil nature of child abuse perpetrators

7. Poor parenting makes child vulnerable to child abuse

8. Contribution of the victim towards being subjected to abuse
First 3 months

$1(1 \%)$

$47(45.2 \%)$

(No specific mention of capital punishment)

3. Inefficiency of law enforcement authorities

4. Evil nature of child abuse perpetrators

5. Feeling sorry for victims / family

6. Blaming political culture for child abuse

7. Cultural apocalypse

8. Blaming parents for child abuse

$\begin{array}{rrrr}2 & (1.9 \%) & 207 & (14.1 \%) \\ 33 & (31.7 \%) & 180 & (12.3 \%) \\ 10 & (9.6 \%) & 111 & (7.6 \%) \\ 2 & (1.9 \%) & 95 & (6.5 \%) \\ 0 & & 43(2.9 \%) \\ 1 & (1 \%) & 32 & (2.2 \%)\end{array}$

Table 4. Discourse analysis of the media coverage on child abuse

First 3 months

$3(7 \%)$

With pictures / photos

With more multiple pictures / photos

More than 5 pictures / photos

Top story of the day

More than one article per day

Editorial

Catchy headlines

Use of pejorative words / harsh tone in the body of article $(n=104)$

$299(20.4 \%)$ $(n=43)$

$121(40.9 \%)$

Second 3 months $(n=1466)$

$403(27.5 \%)$

$1(2.3 \%)$

$84(28.4 \%)$

$32(10.8 \%)$

$5(1.7 \%)$

$26(8.8 \%)$

4 (1.3\%)

99 (33.4\%)

$122(41.2 \%)$ 
Following the incident, almost half of the articles included picture/s, which is in keeping with the media framing theory. Many of the pictures were of victims smiling innocently or of the mother crying incessantly. This was presented in combination with the frequent use of dramatic and pejorative language, such as "evil", "inhumane" and "monster" which may result in a disproportionate fear and increased sense vulnerability. This may contribute to increased anxiety related disorders among children, decreased community tolerance toward people who are alleged to have been involved in child abuse and a sense of urgency in punishing the perpetrators. This phenomena was further illustrated by the uncritical reporting of details of the alleged involvement of three people, who were later cleared of any wrongdoing related to the crime; it appeared to be a declaration of a 'guilty verdict by media' (8). The media portrayal of the victim's father was also biased and stereotypical, which is likely to have further influenced public misconceptions.

The findings of this study demonstrate that print media has a tendency to report child abuse of severe nature without providing details of the social context within which the abuse occurs. It is therefore not surprising that the main image painted of abusers in the media was as evil or bad individuals. Media coverage also concentrated on the more atypical and sensational cases which highlighted the 'irony' and 'incongruity' $(6,8)$. Newsworthiness of the articles was based on stranger cases or extra-familial abusers in socially respectable positions such as teachers abusing students (9). This was significantly overrepresented in media coverage, when compared to the established fact that a majority of perpetrators are often known to the victims. Diversion of attention away from the actuality in this manner, and provision of little or no coverage of underlying social causes of child abuse, limits the ability and opportunity to provide accurate information and education about this important issue.

There appeared to be a clear connection between increased prominence on media coverage on evil nature of perpetrators, as well as lack of trust on authorities in bringing the perpetrators to justice, and the readers' comments on giving capital or severe punishment to perpetrators. While media may simply reflect societal views, it has the capacity to form and change such views (10). This power is misused in distorted, sensational, superficial, and stereotypical media coverage.

Our findings also show that details and pictures of victims and families were widely used in the print media. The freedom of the press to publish is the freedom of the people to be informed. At the same time media should not misuse the liberty to invade people's privacy. Revealing a child victim's identity in the media and using their photographs can be equally, if not more damaging than abuse itself, especially considering the stigma attached to abuse in Sri Lanka.

\section{Limitations}

Our study provided an analysis of the media portrayal of child abuse and public perception of it using the impact of two important child abuse tragedies on same. This study was limited to two Sinhalese newspapers and study period was limited to 6 months. This restricted focus excludes significant proportion of Sri Lankan people and may limit generalisability of the findings.

\section{Conclusion}

It is apparent that the Sri Lankan public is very sensitive to news related to child abuse; therefore the media has an important influence on setting and changing policy agendas, through mobilisation of the public and public opinion. Researchers and journalists have a central role and responsibility in the provision of more accurate and less sensationalized depictions of child abuse, thus minimizing any further harm to victims of abuse, and creating a safer Sri Lanka for children.

\section{Conflicts of interest}

None declared

A Rodrigo, Department of Psychiatry, Faculty of Medicine, University of Kelaniya, Ragama

N Liyanage, Colombo North Teaching Hospital, Ragama

Corresponding author: A Rodrigo

Email: asirir2000@yahoo.com

\section{References}

1. United Nations Children's Fund (UNICEF). Violence against children. UNICEF, 2014. Available at:http:// www.unicef.org/srilanka/VAC(3).pdf (Accessed 01 June, 2016)

2. Abeywardene ASA, Atukorale SH, Abeynayaka KKDCC, Athauda T. A study on knowledge and prevalence of sexual harassment and abuse among schoolboys in Colombo District. SL J Child Health 2004; 33 (1): 9-17.

3. Rodrigo A, Liyanage N. Child abuse: the role of psychiatrists. SL J Psychiatry 2015; 6(2): 1-2.

4. Lonne B, Parton N. Portrayals of child abuse scandals in the media in Australia and England: impacts on practice, policy, and systems: most media coverage distorts the public understandings of the nature of child maltreatment. Child Abuse Negl 2014; 38(5): 822-36.

5. Kitzinger J. Defending innocence: ideologies of childhood. Feminist Review 1988; 28: 77-87. 
6. Souza R. NGOs in India's elite newspapers: a framing analysis. Asian J Communication 2010; 20(4): 477-93.

7. Allyoucanread.com [homepage on internet]. Top 20 Sri Lanka news media, Ontario c2001-16; Available at http:// www.allyoucanread.com/sri-lanka-newspapers/ (Accessed 01 June, 2016)

8. Ducat L, Thomas S, Blood W. Sensationalising sex offenders and sexual recidivism: Impact of the Serious Sex Offender
Monitoring Act 2005 on media reportage. Aus Psychologist 2009; 44(3): 156-65.

9. Wilczynski A, Young K, Sinclair K. Moral tales: representations of child abuse in the quality and tabloid media. ANZ J Criminology 1999; 32(3): 262-83.

10. Goddard C, Saunders BJ. Child abuse and the media. Issues in Child Abuse Prevention 2001; 14: 1-22. 